\title{
Leukoaraiosis Attenuates Diagnostic Accuracy of Large-Vessel Occlusion Scales
}

\author{
(D) Y. Mayasi, (DR.P. Goddeau Jr, (DM. Moonis, (DB. Silver, (D)A.H. Jun-O'Connell, (D)A.S. Puri, and (D) N. Henninger
} o-

\begin{abstract}
BACKGROUND AND PURPOSE: Prehospital stroke scales may help identify patients likely to have large-vessel occlusion to facilitate rapid triage to thrombectomy-capable stroke centers. Scale misclassification may result in inaccurate decisions and possible harm. Pre-existing leukoaraiosis has been shown to attenuate the association between deficit type and stroke severity. We sought to determine whether leukoaraiosis affects the predictive ability of 5 commonly used large-vessel occlusion scales.
\end{abstract}

MATERIALS AND METHODS: We retrospectively analyzed 274 consecutive patients with stroke with available brain MR imaging and vessel imaging. We used the following large-vessel occlusion scales: the 3-Item Stroke Scale; Field Assessment Stroke Triage for Emergency Destination; Rapid Arterial Occlusion Evaluation; Vision, Aphasia, Neglect score; and Cincinnati Prehospital Stroke Severity Scale. For diagnostic scale accuracy, we assessed sensitivity, specificity, positive predictive value, negative predictive value, and $\kappa$. Multivariable logistic regression was used to determine the predictive ability of the scales after adjustment for leukoaraiosis and potential confounders.

RESULTS: In unadjusted analyses, all scales predicted the presence of large-vessel occlusion ( $n=46, P<.01$ each), though diagnostic accuracy was attenuated among patients with moderate-to-severe leukoaraiosis. After adjustment, the Field Assessment Stroke Triage for Emergency Destination ( $\mathrm{OR}=3.2 ; 95 \% \mathrm{Cl}, 1.1-9.5 ; P=.033)$ and Rapid Arterial Occlusion Evaluation ( $\mathrm{OR}=3.7 ; 95 \% \mathrm{Cl}, 1.3-10.8 ; P=.015)$, but not the 3-Item Stroke Scale (OR $=5.4 ; 95 \% \mathrm{Cl}, 0.86-33.9 ; P=.073)$, Vision, Aphasia, Neglect score $(\mathrm{OR}=2.5 ; 95 \% \mathrm{Cl}, 0.8-7.2)$, and Cincinnati Prehospital Stroke Severity Scale (OR $=2.8 ; 95 \% \mathrm{CI}, 1.0-8.0)$, predicted large-vessel occlusion.

CONCLUSIONS: The diagnostic accuracy of the tested large-vessel occlusion scales was attenuated in the presence of moderate-tosevere leukoaraiosis. This information that may aid the design of future studies that require large-vessel occlusion scale screening of patients who are likely to have concomitant leukoaraiosis.

ABBREVIATIONS: CPSSS = Cincinnati Prehospital Stroke Severity Scale; EST = endovascular stroke therapy; FAST-ED = Field Assessment Stroke Triage for Emergency Destination; LVO = large-vessel occlusion; RACE = Rapid Arterial Occlusion Evaluation; 31/SS = 3-Item Stroke Scale; VAN = Vision, Aphasia, Neglect

$\mathbf{R}$ ecent endovascular stroke therapy (EST) trials have shown significantly improved outcomes among patients with largevessel occlusion (LVO). ${ }^{1}$ Reliable prehospital identification of pa-

Received July 7, 2017; accepted after revision October 2.

From the Department of Neurology (Y.M., R.P.G., M.M., B.S., A.H.J.-O., N.H.), Department of Radiology, Division of Neurointerventional Radiology (A.S.P.), and Department of Psychiatry (N.H), University of Massachusetts Medical School, Worcester, Massachusetts.

Dr Henninger is supported by K08NS091499 from the National Institute of Neurological Disorders and Stroke of the National Institutes of Health. The content is solely the responsibility of the authors and does not necessarily represent the official views of the National Institutes of Health.

Please address correspondence to Nils Henninger, MD, PhD, Departments of Neurology and Psychiatry, University of Massachusetts Medical School, 55 Lake Ave, North, Worcester, MA 01655; e-mail: nils.henninger@umassmed.edu

-- Indicates open access to non-subscribers at www.ajnr.org

$\square$ Indicates article with supplemental on-line photos.

http://dx.doi.org/10.3174/ajnr.A5473 tients with LVO and transfer to an EST-capable center are critical because earlier treatment is associated with more favorable outcome. $^{2-5}$

Although the ideal prehospital triage of patients with potential LVO remains uncertain, several clinical scales have been developed to aid identification of patients likely to have an LVO before vascular imaging is available, such as in the prehospital setting or during telestroke consultations. ${ }^{6-10}$ However, these scales have the potential to misclassify patients. ${ }^{11}$ Several factors may attenuate diagnostic accuracy of stroke scales, including stroke location in the posterior circulation, atypical presentation, and the presence of stroke mimics. ${ }^{2,12}$ Inaccurate LVO prediction may delay patient transfer to an endovascular center (falsenegatives) with an increased risk for a worse outcome. ${ }^{13}$ Conversely, unwarranted patient transfer to an EST-capable hospital (false-positives) may overburden the relatively few available EST-capable centers. It is important to understand factors that 
may increase the risk for misclassification to improve prediction accuracy.

Pre-existing leukoaraiosis is identified in most patients with stroke on brain MR imaging as white matter hyperintensities. ${ }^{14}$ Prior studies have shown that leukoaraiosis alters the classic association between the NIHSS deficit and hemispheric lateralization, relates to greater-than-expected NIHSS scores in relation to the acute infarct extent, and worsens outcome after EST. ${ }^{14-17}$ Because most available LVO scales are based on the NIHSS, ${ }^{6-10}$ we sought to determine whether leukoaraiosis severity affects the diagnostic accuracy of several previously developed prehospital stroke scales. ${ }^{6-10}$ We hypothesized that the diagnostic scale performance is reduced among patients with stroke with moderate-to-severe pre-existing leukoaraiosis. Clarifying this issue may aid clinical study design and choice of LVO scales to more reliably identify patients with stroke with LVO in the prehospital setting when neuroimaging data are unavailable, and it is expected that a substantial proportion of screened patients will have advanced leukoaraiosis.

\section{MATERIALS AND METHODS \\ Study Cohort}

We retrospectively analyzed 274 consecutive patients with acute ischemic stroke shown on brain MR imaging who were included in the University of Massachusetts Memorial Medical Center Stroke Registry between January 2013 and January 2014. ${ }^{15,18} \mathrm{~Pa}-$ tient demographics, laboratory data, comorbidities, preadmission medications, and stroke pathogenesis (using the Causative Classification System for Ischemic Stroke as previously described $^{15,18}$ ) after completion of diagnostic evaluation were collected on all patients. NIHSS scores were assessed at the time of presentation by members of the stroke team certified in the NIHSS. Only patients with complete details on all NIHSS subcategories were included (On-line Fig 1). All patients underwent head CT and either CTA $(n=249)$ or MRA $(n=25)$ at admission. Ten patients underwent both CTA and MRA. To reliably determine the white matter lesion burden (leukoaraiosis), we only included patients with available brain MR imaging. Our investigation was approved by our Institutional Review Board (No. H00006964), and a Health Insurance Portability and Accountability Act waiver of informed consent was granted. We adhere to the Strengthening the Reporting of Observational Studies in Epidemiology (www.strobe-statement.org) and Standards for Reporting of Diagnostic Accuracy Studies (www.stard-statement. org) guidelines.

\section{Neuroimaging Protocol}

All MR imaging and MRA sequences were acquired on a $1.5 \mathrm{~T}$ whole-body MR imaging scanner (Signa HD; GE Healthcare, Milwaukee, Wisconsin) between 1 and 7 days after stroke. Brain MR imaging sequences included T1, T2, FLAIR, and DWI. DWI was performed with echo-planar imaging with a TR of $8000 \mathrm{~ms}$, TE of $102 \mathrm{~ms}$, FOV of $22 \times 22 \mathrm{~cm}$, image matrix of $128 \times 128$, slice thickness of $5 \mathrm{~mm}$ with a 1-mm interslice gap, and b-values of 0 and $1000 \mathrm{~s} / \mathrm{mm}^{2}$. FLAIR was performed with a TR of $9002 \mathrm{~ms}$, TE of $143 \mathrm{~ms}$, FOV of $22 \times 22 \mathrm{~cm}$, image matrix of $256 \times 224$, and slice thickness of $6 \mathrm{~mm}$ with a 1-mm interslice gap. All MRA was performed with TOF-echo-spoiled gradient-echo pulse sequences. Head MRA was performed with a TR of $25 \mathrm{~ms}$, flip angle of $20^{\circ}$, FOV of $20 \mathrm{~cm}$, matrix of $256 \times 224$, and slice thickness of $1.4 \mathrm{~mm}$. Neck MRA performed with contrast used a TE of 1.8, flip angle of $45^{\circ}$, FOV of 33, slice thickness of $1 \mathrm{~mm}$, and matrix of $28.4 \times 22.4 \mathrm{~cm}$. Patients received $20 \mathrm{~mL}$ of gadobenate dimeglumine (MultiHance; Bracco Diagnostics, Princeton, New Jersey). Neck MRA was performed without contrast with a TR of $24 \mathrm{~ms}$, TE of $5.1 \mathrm{~ms}$, flip angle of $60^{\circ}$, FOV of 20 , slice thickness of 1.5 $\mathrm{mm}$, and matrix of $512 \times 160$.

All CT sequences were obtained on a 64-detector row scanner (Brilliance; Philips Healthcare, Best, the Netherlands). ${ }^{17,19}$ CT was performed in a nonhelical mode at $120 \mathrm{kV}$ (peak) and $200 \mathrm{~mA}$, with data reconstruction at $5-\mathrm{mm}$ axial sections. CTA was performed using a $64 \times 0.625 \mathrm{~mm}$ detector configuration with a pitch of 0.673 from the arch of the aorta to the vertex using 120 $\mathrm{kV}(\mathrm{p}), 300 \mathrm{~mA}$, and 0.5-second rotation time. Patients received $60-80 \mathrm{~mL}$ of iopamidol (Isovue 370; Bracco Diagnostics) in the antecubital vein at a rate of $4 \mathrm{~mL} / \mathrm{s}$ through a power injector, followed by $40 \mathrm{~mL}$ of saline. 3D orthogonal MIP images were created in 3 planes.

\section{Leukoaraiosis Grading}

In all patients, leukoaraiosis was defined on MR imaging as supratentorial white matter FLAIR hyperintensity lesions according to the Standards for Reporting Vascular Changes on Neuroimaging $^{20}$ criteria and graded according to the Fazekas scale as previously described in detail. ${ }^{14,15}$ The total Fazekas scale score was calculated by adding the periventricular and subcortical scores. ${ }^{14}$ We have previously shown substantial interrater reliability with an intraclass correlation coefficient of 0.969 (95\% CI, $0.943-$ 0.983). ${ }^{14}$ In addition, we dichotomized the degree of leukoaraiosis according to the median Fazekas scale score to $0-2(n=145$, absent-to-mild leukoaraiosis) versus 3-6 ( $n=129$, moderate-tosevere leukoaraiosis) for statistical purposes.

\section{Definition of Large-Vessel Occlusion}

Large-vessel occlusion was defined on the admission CTA or MRA as the presence of an apparent occlusion of the intracranial internal carotid artery and proximal middle cerebral artery (M1). The included prehospital stroke scales were not designed to assess the presence of occlusion in the distal MCA (M2), basilar, and intracranial vertebral arteries. Therefore, occlusion in these vessels was considered non-LVO for this study, and only considered in the exploratory analyses. All images were reviewed by a neuroradiologist as part of the routine clinical work-up. The site of the LVO was abstracted from the radiologic report and by cross-validating with the original scans by one of the authors (Y.M.), who was masked to clinical data. Discrepant interpretations were resolved by consensus after review by a second neurologist (N.H.).

\section{Prehospital Stroke Scales}

To determine the impact of pre-existing leukoaraiosis on LVO prediction, we examined 5 previously published scales that could be reliably reconstructed by abstraction from the admission NIHSS score sheet and the detailed neurologic examination documented in our medical records. We used the following addi- 
Table 1: Baseline characteristics (unadjusted) of the studied patient population as stratified by the presence-versus-absence of proximal LVO $^{a}$

\begin{tabular}{|c|c|c|c|c|}
\hline Characteristics & $\begin{array}{l}\text { All Patients } \\
(n=274)\end{array}$ & $\begin{array}{c}\text { LVO } \\
(n=46)\end{array}$ & $\begin{array}{l}\text { No LVO } \\
(n=228)\end{array}$ & $\begin{array}{c}P \\
\text { Value }\end{array}$ \\
\hline Age (yr) & $69(60-80)$ & $68(58-77)$ & $70(60-81)$ & .347 \\
\hline Female sex & $126(46 \%)$ & $24(52 \%)$ & $102(45 \%)$ & .418 \\
\hline Admission NIHSS score & $5(2-10)$ & $14(4-17)$ & $4(2-9)$ & $<.001$ \\
\hline Prestroke mRS & $0(0-1)$ & $0(0-1)$ & $0(0-1)$ & .774 \\
\hline \multicolumn{5}{|l|}{ LVO stroke scale scores } \\
\hline $31 / S S$ & $1(0-2)$ & $2(1-3)$ & $1(0-2)$ & $<.001$ \\
\hline VAN & $0(1-2)$ & $3(0-4)$ & $0(0-2)$ & $<.001$ \\
\hline CPSSS & $0(0-1)$ & $1(0-3)$ & $0(0-1)$ & .001 \\
\hline FAST-ED & $2(0-4)$ & $4(2-6)$ & $1(0-3)$ & $<.001$ \\
\hline RACE & $2(0-4)$ & $5(1-7)$ & $1(0-3)$ & $<.001$ \\
\hline \multicolumn{5}{|l|}{ Laboratory data } \\
\hline Admission glucose level (mg/dL) & 119 (100-142) & $120(105-143)$ & 119 (99-142) & .515 \\
\hline Admission creatinine level (mg/dL) & $0.95(0.78-1.20)$ & $0.90(0.73-1.0)$ & $0.97(0.79-1.20)$ & .090 \\
\hline HbAlc level $(\%)(n=161)$ & $5.9(5.7-6.5)$ & $6.0(5.6-6.3)$ & $5.9(5.7-6.6)$ & .794 \\
\hline LDLc level (mg/dL) $(n=171)$ & $93(72-123)$ & $89(65-111)$ & 94 (74-123) & .274 \\
\hline \multicolumn{5}{|l|}{ Neuroimaging } \\
\hline Fazekas scale score (0-2) & $129(48 \%)$ & $30(65 \%)$ & $99(43 \%)$ & .009 \\
\hline \multicolumn{5}{|l|}{ Pre-existing risk factors } \\
\hline Hypertension & $210(77 \%)$ & $34(74 \%)$ & $176(77 \%)$ & .703 \\
\hline Hyperlipidemia & $152(56 \%)$ & $26(57 \%)$ & $132(58 \%)$ & .076 \\
\hline Diabetes & $75(27 \%)$ & $11(24 \%)$ & $64(28 \%)$ & .594 \\
\hline Prior stroke or TIA & $59(22 \%)$ & $6(13 \%)$ & $53(23 \%)$ & .168 \\
\hline Atrial fibrillation & $42(15 \%)$ & $8(17 \%)$ & $34(15 \%)$ & .823 \\
\hline Coronary artery disease & $58(21 \%)$ & $4(9 \%)$ & $54(24 \%)$ & .028 \\
\hline Congestive heart failure & $20(7 \%)$ & $1(2 \%)$ & $19(8 \%)$ & .215 \\
\hline Peripheral arterial disease & $18(7 \%)$ & $1(2 \%)$ & $17(8 \%)$ & .221 \\
\hline \multicolumn{5}{|l|}{ Preadmission medications } \\
\hline Statin & $124(45 \%)$ & $19(41 \%)$ & $105(46 \%)$ & .689 \\
\hline Antihypertensive & $185(67 \%)$ & $32(70 \%)$ & $153(67 \%)$ & .863 \\
\hline Antiglycemic & $53(19 \%)$ & $9(20 \%)$ & $44(19 \%)$ & 1.000 \\
\hline Antiplatelets & $145(53 \%)$ & $24(52 \%)$ & $121(53 \%)$ & 1.000 \\
\hline Oral anticoagulant & $19(7 \%)$ & $4(9 \%)$ & $15(7 \%)$ & .749 \\
\hline
\end{tabular}

Note:-HbAlc indicates glycated hemoglobin Alc; LDLc, low-density lipoprotein cholesterol.

a Proximal LVO is defined as an occlusion of the internal carotid artery or middle cerebral artery M1 segment. Data are No. (\%) or median (25th-75th percentile).

tional prespecified rules for derivation of the scores because we previously found that severe leukoaraiosis substantially attenuates the classic hemispheric lateralization of the NIHSS deficit ${ }^{15}$ : If both sides were weak, the weaker side determined the sign scored; and if both sides were equally weak, the presence of the sign was scored.

The Field Assessment Stroke Triage for Emergency Destination (FAST-ED) was calculated on the basis of the presence of facial palsy (scored $0-1)$, arm weakness $(0-2)$, speech changes $(0-2)$, eye deviation $(0-2)$, and denial/neglect $(0-2)$. A score of $\geq 4$ was considered suggestive of LVO. ${ }^{9}$ The Rapid Arterial Occlusion Evaluation (RACE) was calculated on the basis of the presence of facial palsy $(0-2)$, arm motor function $(0-2)$, leg motor function $(0-2)$, gaze $(0-1)$, and aphasia or agnosia (0-2). A score $\geq 5$ was considered indicative of LVO. ${ }^{8}$ The Vision, Aphasia, Neglect (VAN) score was calculated on the basis of the presence of arm motor weakness $(0-1)$ plus the presence of visual disturbance (blindness, field cut, diplopia [0-1]), aphasia (0-1), and neglect (including forced gaze deviation $[0-1]$ ). In the absence of arm weakness, the patient received a score of zero. A score $\geq 2$ was considered indicative of LVO. ${ }^{6}$ The Cincinnati Prehospital Stroke Severity Scale (CPSSS) was calculated on the basis of the presence of conjugate gaze deviation, (0-2), arm weakness (0-1), and impaired consciousness $(0-1)$. A score of $\geq 2$ was considered indic- ative of LVO. ${ }^{10}$ The 3-Item Stroke Scale (3I/SS) was calculated on the basis of the level of consciousness (0-2), gaze deviation (0-2), and hemiparesis (0-2). A score $\geq 4$ was considered indicative of LVO. $^{7}$

\section{Statistics}

Unless otherwise stated, continuous variables are reported as mean $\pm \mathrm{SD}$ or median (25th-75th percentile). Categoric variables are reported as proportions. Between-group comparisons for continuous and ordinal variables were performed with the Mann-Whitney $U$ test. Categoric variables were compared using the $\chi^{2}$ test or Fisher exact test as appropriate. To determine the diagnostic accuracy of the LVO scales, we calculated the area under receiver operating curves (C statistics, ordinal scales) as well as sensitivity, specificity, positive predictive value, negative predictive value, and $\kappa$ (dichotomized scales each) with corresponding 95\% CIs.

We created multivariable logistic regression models to determine whether the tested LVO scale cutoffs predicted large-artery occlusion (dependent variable) independent of leukoaraiosis (as determined by the Fazekas scale score). All models were adjusted for factors known to be associated with leukoaraiosis, including age, sex, and preadmission mRS and a history of hypertension, stroke/TIA, and atrial fibrillation. In addition, models were adjusted for the Fazekas scale score $\times$ LVO Scale Interaction to determine whether the leukoaraiosis burden differentially modified the predictive ability of the tested scales. Variables were sequentially removed (likelihood ratio) from the models at a significance level of 0.1 to avoid model overfitting. Collinearity diagnostics were performed (and its presence rejected) for all multivariable regression models. The Hosmer-Lemeshow goodness-of-fit statistic was used to assess model fit.

Two-sided significance tests were used throughout; unless stated otherwise, a 2 -sided $P<.05$ was considered statistically significant. All statistical analyses were performed with SPSS, Version 22 (IBM, Armonk, New York).

\section{RESULTS}

Of 502 patients with ischemic stroke, 274 fulfilled the study criteria and were included in the analysis (On-line Fig 1).

Baseline characteristics of included patients stratified by the presence of LVO are summarized in Table 1. Overall, 46 patients had a proximal LVO (17\%), and 228 (83\%) patients had no LVO. Baseline characteristics of the included patients were well-balanced except for a higher NIHSS $(P<.001)$ and Fazekas scale score $(P=.009)$ among patients with LVO. The relative distribu- 


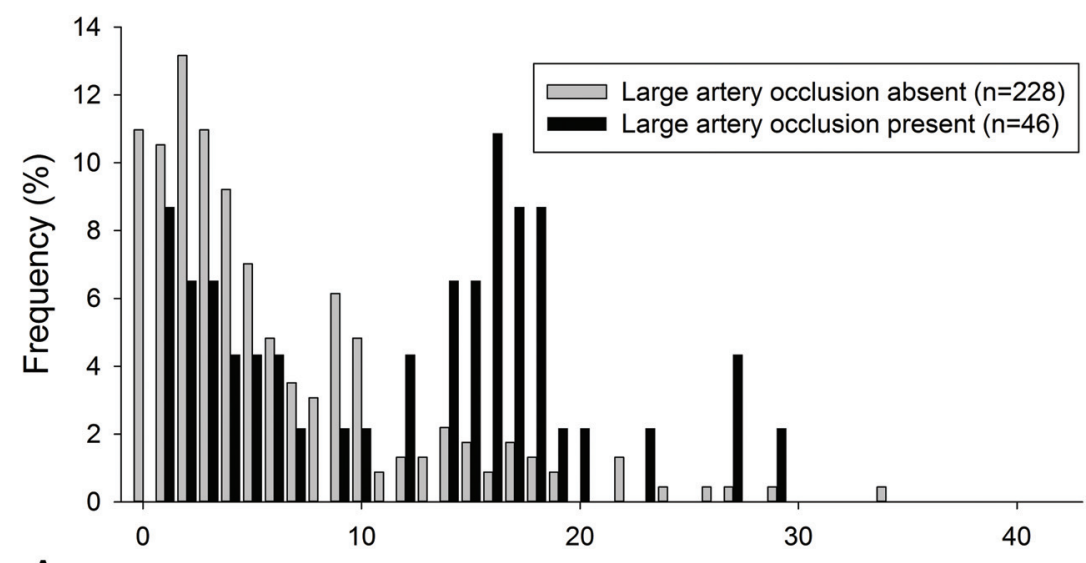

A

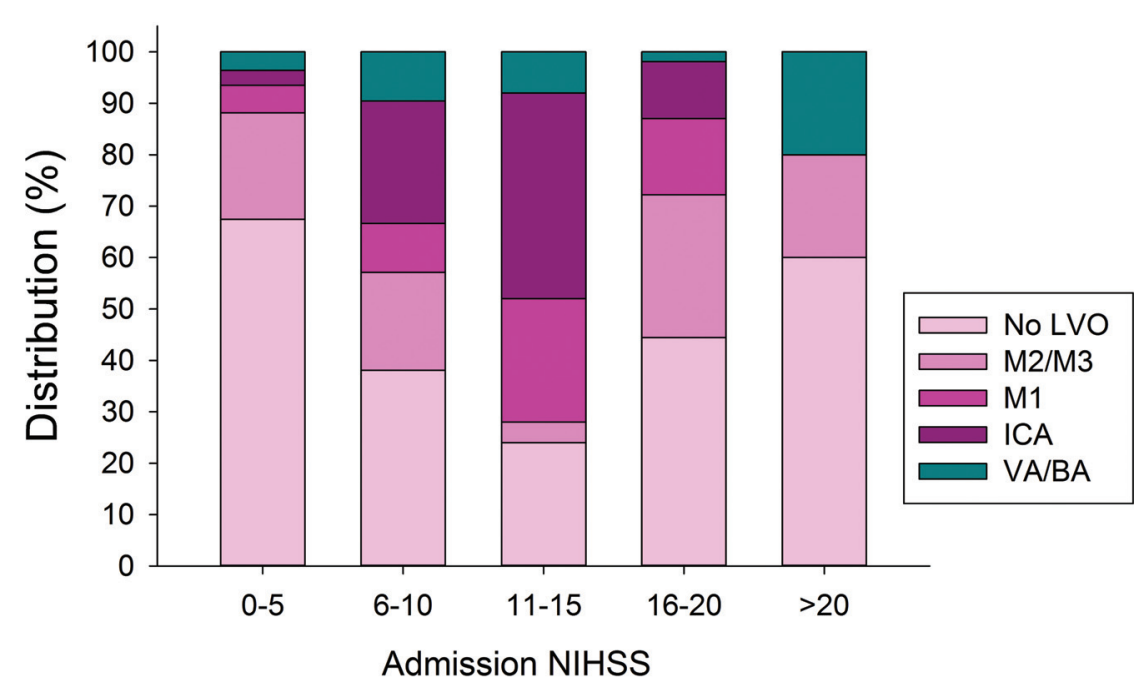

B

56

25

26

12

FIGURE. NIHSS and LVO distribution in the tested cohort. A, Relative frequency of NIHSS scores as stratified by the presence-versus-absence of large-artery occlusion. B, Distribution of NIHSS scores according to large-artery occlusion status. There was no difference in the distribution of NIHSS scores (bins) between subjects with absent-to-mild versus moderate-to-severe leukoaraiosis $\left(P=.319, \chi^{2}\right.$ test $)$.

tion of the NIHSS scores and types of arterial occlusion in the included patients are summarized in the Figure.

On-line Fig 2 shows the percentage of LVO cases that would have gone unidentified across different LVO score thresholds. On average, more cases would have gone unnoticed in patients with moderate-to-severe leukoaraiosis compared with those with only absent-to-mild leukoaraiosis.

Table 2 summarizes the diagnostic accuracy of the established LVO scale cutoffs both in the entire cohort and when stratified by leukoaraiosis. Overall, the diagnostic accuracy was modest in the entire cohort and further attenuated among patients with moderate-to-severe leukoaraiosis.

We calculated the area under receiver operating curve to examine the diagnostic performance of the 5 tested prehospital LVO scales for the presence of a proximal LVO as an ordinal variable in the entire cohort as well as stratified by leukoaraiosis burden (On-line Fig $3 A-C)$. All scales predicted LVO in the entire cohort $(P<.01$ each, Table 3$)$ and in patients with absent-to-mild leukoaraiosis $(P<.001$ each). However, none 
Table 2: Diagnostic accuracy of prehospital stroke scales in predicting LVO stratified by leukoaraiosis severity ${ }^{\mathrm{a}}$

\begin{tabular}{lccccc}
\multicolumn{1}{c}{ Scale } & Sensitivity (\%) & Specificity (\%) & PPV (\%) & NPV (\%) & $\boldsymbol{\kappa}$ \\
\hline $3 I / S S \geq 4$ & & & Total cohort $(n=274)$ & & \\
VAN $\geq 2$ & $22(11-36)$ & $90(86-94)$ & $31(19-47)$ & $85(83-87)$ & $0.14(0-0.28)$ \\
CPSSS $\geq 2$ & $70(54-82)$ & $63(57-69)$ & $28(23-33)$ & $91(87-94)$ & $0.20(0.10-0.30)$ \\
RACE $\geq 5$ & $41(27-57)$ & $79(74-84)$ & $29(19-47)$ & $87(84-90)$ & $0.18(0.05-0.31)$ \\
FAST-ED $\geq 4$ & $50(35-65)$ & $85(80-89)$ & $40(31-51)$ & $89(86-92)$ & $0.32(0.18-0.46)$ \\
& $57(41-71)$ & $79(73-84)$ & $35(27-43)$ & $90(83-87)$ & $0.28(0.15-0.41)$ \\
$31 / S S \geq 4$ & & Absent-to-mild leukoaraiosis (Fazekas scale score, 0-2; $n=129)$ & \\
VAN $\geq 2$ & $50(21-79)$ & $88(80-94)$ & $33(18-52)$ & $94(89-96)$ & $0.09(0-0.27)$ \\
CPSSS $\geq 2$ & $73(54-88)$ & $68(58-77)$ & $41(32-50)$ & $89(82-94)$ & $0.32(0.16-0.48)$ \\
RACE $\geq 5$ & $37(20-56)$ & $87(79-93)$ & $46(30-63)$ & $82(77-86)$ & $0.25(0.06-0.45)$ \\
FAST-ED $\geq 4$ & $53(34-72)$ & $91(83-96)$ & $64(46-78)$ & $87(81-90)$ & $0.47(0.29-0.65)$ \\
& $57(37-75)$ & $84(75-90)$ & $52(38-65)$ & $86(81-91)$ & $0.39(0.09-0.57)$ \\
$3 I / S S \geq 4$ & & $92)$ & \\
VAN $\geq 2$ & $25(7-52)$ & $92(86-96)$ & $29(12-53)$ & $91(88-93)$ & $0.18(0-0.41)$ \\
CPSSS $\geq 2$ & $63(35-85)$ & $60(51-68)$ & $16(11-23)$ & $93(87-96)$ & $0.10(0-0.22)$ \\
RACE $\geq 5$ & $50(25-75)$ & $74(65-81)$ & $19(12-29)$ & $92(88-95)$ & $0.14(0-0.29)$ \\
FAST-ED $\geq 4$ & $44(20-70)$ & $81(73-87)$ & $22(13-35)$ & $92(88-94)$ & $0.17(0-0.35)$ \\
\hline
\end{tabular}

Note:-NPV indicates negative predictive value; PPV, positive predictive value.

${ }^{a}$ Data in parentheses are $95 \% \mathrm{Cl}$.

Table 3: Multivariable logistic regression analysis for the ability of previously defined clinical stroke scale cutoffs to predict large-vessel occlusion in the examined cohort

\begin{tabular}{lcccc}
\hline Stroke Scale & Crude OR $(95 \% \mathrm{Cl})$ & $\boldsymbol{P}$ Value & ${\text { Adjusted OR }(95 \% \mathrm{CI})^{\mathbf{a}}}$ & $\boldsymbol{P}$ Value \\
\hline $3 \mathrm{I} / \mathrm{SS} \geq 4$ & $4.736(1.513-14.826)$ & .008 & $5.389(0.856-33.908)$ & .073 \\
VAN $\geq 2$ & $3.918(1.979-7.760)$ & $<.001$ & $2.468(0.845-7.206)$ & .098 \\
CPSSS $\geq 2$ & $2.710(1.388-5.290)$ & .003 & $2.794(0.973-8.028)$ & .056 \\
RACE $\geq 5$ & $5.706(2.881-11.299)$ & $<.001$ & $3.236(1.099-9.527)$ & .033 \\
FAST-ED $\geq 4$ & $4.749(2.447-9.217)$ & $<.001$ & $3.740(1.291-10.839)$ & .015 \\
\hline
\end{tabular}

${ }^{a}$ Each model was adjusted for leukoaraiosis burden (as determined by the Fazekas scale score) as well as Leukoaraiosis $x$ Stroke Scale Interaction. When additionally entered into the model, the prestroke modified Rankin Scale, age, sex, hypertension, history of stroke/transient ischemic attack, and atrial fibrillation were not retained in the final step of the analysis. In all analyses, leukoaraiosis and stroke scales were entered as dichotomized variables. When all analyses were repeated by entering the Fazekas scale score and stroke scale scores as ordinal variables, the VAN $(P=.029)$, CPSSS $(P=$ .024), FAST-ED $(P=.003)$, RACE $(P=.002)$, and $31 / \mathrm{SS}(P=.006)$ scores predicted LVO independent of the leukoaraiosis burden (not shown). There was no Leukoaraiosis $\times$ Stroke Scale Interaction in any of the examined models $(P>.05$, each).

ate availability or because repeat CTA is not desirable to avoid repeat imaging at the EST-capable hub hospital. ${ }^{25,26}$ Leukoaraiosis has been repeatedly shown to confer an increased risk of poor outcome in patients with LVO, including those undergoing EST. ${ }^{17,19}$ Arguably, the presence of severe leukoaraiosis could thus prompt CTA at an outside hospital (versus transfer without CTA) to minimize the cost associated with unnecessary transfers. ${ }^{27}$ However, to date, no study has shown that patients with severe leukoaraiosis do not benefit from EST. Accordingly, our data should not direct medical decision-making. Nevertheless, one could envision that the presence of specific, yet-to-be-defined, clinical patient characteristics trigger "prescreening" of patients with CTA to aid transfer decisions. Such factors may be very old age, prestroke functional status, and cognitive impairment, which have been associated with leukoaraiosis and limited benefit from EST. ${ }^{28}$

The strengths of our study relate to inclusion of consecutive patients with available MR imaging, imaging assessment by experienced examiners, and adjustment for important factors associated with leukoaraiosis and stroke severity. Limitations relate to the retrospective and observational nature of the study, as well as the inclusion of a moderately sized single- center cohort. In this respect, the overall diagnostic accuracy of the tested scales was only modest in our cohort. This result may be partially explained by our hospital-based study, which only included patients with proved stroke and who had available vessel imaging because the diagnostic accuracy is sensitive to the characteristics (disease prevalence and spectrum) of the tested population. Nevertheless, our results are in line with observations from other hospital-based studies suggesting generalizability of our results. ${ }^{29,30}$ Last, due to our study design, we only examined LVO stroke scales based on the NIHSS. Accordingly, our results may not translate to other scales and should be interpreted cautiously.

\section{CONCLUSIONS}

Our results indicate that the presence of moderate-to-severe leukoaraiosis attenuates the diagnostic accuracy of available LVO scales and that the RACE and FAST-ED scales appeared more resilient to the confounding effects of leukoaraiosis. If confirmed in a larger cohort, this information may aid the design of studies that require prehospital LVO scale screening of patients likely to have concomitant leukoaraiosis.

Disclosures: Brian Silver-UNRELATED: Consultancy: Women's Health Initiative, $\mathrm{Na}$ tional Institutes of Health; Employment: Joint Commission; Expert Testimony, Comments: medicolegal malpractice; Patents (Planned, Pending or Issued): transcranial magnetic stimulation; Payment for Development of Educational Presentations: Ebix, MedLink, Medscape. Ajit Puri-UNRELATED: Consultancy: Stryker, Codman; Grants/Grants Pending: Stryker, Medtronic, Comments: research grants*; Payment for Lectures Including Service on Speakers Bureaus: Stryker; Stock/Stock Options: InNeuroCo. Nils Henninger-RELATED: Grant: National Institute of Neurological Disorders and Stroke, Comments: K08*; UNRELATED: Board Membership: Omniox, Comments: Advisory Board member; Other: Oak Ridge Associated Universities, Comments: ad hoc reviewer. ${ }^{*}$ Money paid to the institution. 


\section{REFERENCES}

1. Goyal M, Hill MD, Saver JL, et al. Challenges and opportunities of endovascular stroke therapy. Ann Neurol 2016;79:11-17 CrossRef Medline

2. Zhao H, Coote S, Pesavento L, et al. Large vessel occlusion scales increase delivery to endovascular centers without excessive harm from misclassifications. Stroke 2017;48:568-73 CrossRef Medline

3. Skagen K, Skjelland M, Russell D, et al. Large-vessel occlusion stroke: effect of recanalization on outcome depends on the National Institutes of Health Stroke Scale score. J Stroke Cerebrovasc Dis 2015;24: 1532-39 CrossRef Medline

4. Saver JL, Goyal M, van der Lugt A, et al; HERMES Collaborators. Time to treatment with endovascular thrombectomy and outcomes from ischemic stroke: a meta-analysis. JAMA 2016;316:1279-88 CrossRef Medline

5. Chen CJ, Ding D, Starke RM, et al. Endovascular vs medical management of acute ischemic stroke. Neurology 2015;85:1980-90 CrossRef Medline

6. Teleb MS, Ver Hage A, Carter J, et al. Stroke vision, aphasia, neglect (VAN) assessment-a novel emergent large vessel occlusion screening tool: pilot study and comparison with current clinical severity indices. J Neurointerv Surg 2017;9:122-26 CrossRef Medline

7. Singer OC, Dvorak F, du Mesnil de Rochemont R, et al. A simple 3-item stroke scale: comparison with the National Institutes of Health Stroke Scale and prediction of middle cerebral artery occlusion. Stroke 2005;36:773-76 CrossRef Medline

8. Pérez de la Ossa N, Carrera D, Gorchs M, et al. Design and validation of a prehospital stroke scale to predict large arterial occlusion: the rapid arterial occlusion evaluation scale. Stroke 2014;45:87-91 CrossRef Medline

9. Lima FO, Silva GS, Furie KL, et al. Field assessment stroke triage for emergency destination: a simple and accurate prehospital scale to detect large vessel occlusion strokes. Stroke 2016;47:1997-2002 CrossRef Medline

10. Katz BS, McMullan JT, Sucharew H, et al. Design and validation of a pre-hospital scale to predict stroke severity: Cincinnati Prehospital Stroke Severity Scale. Stroke 2015;46:1508-12 CrossRef Medline

11. Scheitz JF, Abdul-Rahim AH, MacIsaac RL, et al. Clinical selection strategies to identify ischemic stroke patients with large anterior vessel occlusion: results from SITS-ISTR (Safe Implementation of Thrombolysis in Stroke International Stroke Thrombolysis Registry). Stroke 2017;48:290-97 CrossRef Medline

12. Kasner SE. Clinical interpretation and use of stroke scales. Lancet Neurol 2006;5:603-12 CrossRef Medline

13. Mohamad NF, Hastrup S, Rasmussen M, et al. Bypassing primary stroke centre reduces delay and improves outcomes for patients with large vessel occlusion. Eur Stroke J 2016;1:85-92 CrossRef

14. Helenius J, Henninger N. Leukoaraiosis burden significantly modulates the association between infarct volume and National Institutes of Health Stroke Scale in ischemic stroke. Stroke 2015;46: 1857-63 CrossRef Medline

15. Helenius J, Goddeau RP Jr, Moonis M, et al. Impact of leukoaraiosis burden on hemispheric lateralization of the National Institutes of
Health Stroke Scale deficit in acute ischemic stroke. Stroke 2016;47: 24-30 CrossRef Medline

16. Onteddu SR, Goddeau RP Jr, Minaeian A, et al. Clinical impact of leukoaraiosis burden and chronological age on neurological deficit recovery and 90-day outcome after minor ischemic stroke. J Neurol Sci 2015;359:418-23 CrossRef Medline

17. Zhang J, Puri AS, Khan MA, et al. Leukoaraiosis predicts a poor 90-day outcome after endovascular stroke therapy. AJNR Am J Neuroradiol 2014;35:2070-75 CrossRef Medline

18. Henninger N, Goddeau RP Jr, Karmarkar A, et al. Atrial fibrillation is associated with a worse 90-day outcome than other cardioembolic stroke subtypes. Stroke 2016;47:1486-92 CrossRef Medline

19. Henninger N, Lin E, Baker SP, et al. Leukoaraiosis predicts poor 90-day outcome after acute large cerebral artery occlusion. Cerebrovasc Dis 2012;33:525-31 CrossRef Medline

20. Wardlaw JM, Smith EE, Biessels GJ, et al; STandards for ReportIng Vascular changes on nEuroimaging (STRIVE v1). Neuroimaging standards for research into small vessel disease and its contribution to ageing and neurodegeneration. Lancet Neurol 2013;12:822-38 CrossRef Medline

21. Rinaldo L, Brinjikji W, Rabinstein AA. Transfer to high-volume centers associated with reduced mortality after endovascular treatment of acute stroke. Stroke 2017;48:1316-21 CrossRef Medline

22. Southerland AM, Johnston KC, Molina CA, et al. Suspected large vessel occlusion: should emergency medical services transport to the nearest primary stroke center or bypass to a comprehensive stroke center with endovascular capabilities? Stroke 2016;47: 1965-67 CrossRef Medline

23. Nogueira RG, Silva GS, Lima FO, et al. The FAST-ED App: a smartphone platform for the field triage of patients with stroke. Stroke 2017;48:1278-84 CrossRef Medline

24. Akbik F, Hirsch JA, Chandra RV, et al. Telestroke-the promise and the challenge, Part one: growth and current practice. J Neurointerv Surg 2017;9:357-60 CrossRef Medline

25. Srivastava PV, Sudhan $P$, Khurana D, et al. Telestroke a viable option to improve stroke care in India. Int J Stroke 2014;9(suppl A100): 133-34 CrossRef Medline

26. Schwamm LH, Rosenthal ES, Hirshberg A, et al. Virtual TeleStroke support for the emergency department evaluation of acute stroke. Acad Emerg Med 2004;11:1193-97 CrossRef Medline

27. Liang JW, Stein L, Wilson N, et al. Timing of vessel imaging for suspected large vessel occlusions does not affect groin puncture time in transfer patients with stroke. J Neurointerv Surg 2017 Jan 24. [Epub ahead of print] CrossRef Medline

28. Khan MA, Baird GL, Miller D, et al. Endovascular treatment of acute ischemic stroke in nonagenarians compared with younger patients in a multicenter cohort. J Neurointerv Surg 2017;9:727-31 CrossRef Medline

29. Heldner MR, Hsieh K, Broeg-Morvay A, et al. Clinical prediction of large vessel occlusion in anterior circulation stroke: mission impossible? J Neurol 2016;263:1633-40 CrossRef Medline

30. Hastrup S, Damgaard D, Johnsen SP, et al. Prehospital acute stroke severity scale to predict large artery occlusion: design and comparison with other scales. Stroke 2016;47:1772-76 CrossRef Medline 